\title{
BMJ Open Investigation of perioperative work processes in provision of antibiotic prophylaxis: a prospective descriptive qualitative study across surgical specialties in Norway
}

\author{
Hilde Valen Wæhle, ${ }^{1,2}$ Stig Harthug, ${ }^{1,2}$ Eirik Søfteland, ${ }^{3,4}$ Nick Sevdalis, ${ }^{5}$ \\ Ingrid Smith, ${ }^{6}$ Siri Wiig, ${ }^{7}$ Karina Aase, ${ }^{7}$ Arvid Steinar Haugen ${ }^{3}$
}

To cite: Wæhle HV, Harthug S, Søfteland $\mathrm{E}$, et al. Investigation of perioperative work processes in provision of antibiotic prophylaxis: a prospective descriptive qualitative study across surgical specialties in Norway. BMJ Open 2019;9:e029671. doi:10.1136/ bmjopen-2019-029671

\section{- Prepublication history for} this paper is available online. To view these files, please visit the journal online (http://dx.doi. org/10.1136/bmjopen-2019029671).

Received 4 February 2019 Revised 5 April 2019 Accepted 17 May 2019
D) Check for updates

(c) Author(s) (or their employer(s)) 2019. Re-use permitted under CC BY-NC. No commercial re-use. See rights and permissions. Published by BMJ.

For numbered affiliations see end of article.

\section{Correspondence to} MSc Hilde Valen Wæhle; hilde.valen.waehle@helsebergen.no

\section{ABSTRACT}

Objective Surgical site infections are known postoperative complications, yet the most preventable of healthcare-associated infections. Correct provision of surgical antibiotic prophylaxis (SAP) is crucial. Use of the WHO Safe Surgical Checklist (SSC) has been reported to improve provision of SAP, and reduce infections postoperatively. To understand possible mechanisms and interactions generating such effects, we explored the underlying work processes of SAP provision and SSC performance at the intersection of perioperative procedures and actual team working.

Design An ethnographic study including observations and in-depth interviews. A combination of deductive and inductive content analysis of the data was conducted.

Setting Operating theatres with different surgical specialities, in three Norwegian hospitals.

Participants Observations of perioperative team working (40 hours) and in-depth interviews of 19 experienced perioperative team members were conducted. Interview participants followed a maximum variation purposive sampling strategy.

Results Analysis identified provision of SAP as a process of linked activities; sequenced, yet disconnected in time and space throughout the perioperative phase. Provision of SAP was handled in relation to several interactive factors: preparation and administration, prescription accuracy, diversity of prescription order systems, patient-specific conditions and changes in operating theatre schedules. However, prescription checks were performed either as formal SSC reviews of SAP items or as informal checks of relevant documents. In addition, use of cognitive reminders and clinical experiences were identified as mechanisms used to enable administration of SAP within the $60 \mathrm{~min}$ timeframe described in the SSC.

Conclusion Provision of SAP was identified as a complex process. Yet, a key element in provision of SAP was the given 60 min. timeframe of administration before incision, provided in the SSC. Thus, the SSC seems beneficial in supporting timely SAP administration practice by either being a cognitive tool and/or as a cognitive intervention.
Strengths and limitations of this study

- This study builds on previous work investigating the impact of the WHO Safe Surgical Checklist implementation on perioperative work processes including provision of antibiotic prophylaxis.

- It shows perspectives on provision of antibiotic prophylaxis by all members represented in the multidisciplinary perioperative team, using purposive sampling strategy in selecting participants for single, in-depth interviews.

- It provides detailed, first-hand observations of everyday work processes on antibiotic prophylaxis across different surgical specialties, including the WHO Safe Surgical Checklist antibiotic items.

- The extent to which identified elements in the work processes of antibiotic prophylaxis can be influenced and further lead to improved provision of prophylaxis remains to be tested.

- The findings might not be generalisable across countries due to organisational and cultural differences.

\section{INTRODUCTION}

Surgical site infections (SSIs) are associated with substantial morbidity and mortality, prolonged hospital stay and increased costs. ${ }^{1-3}$ Although SSI incidence is higher in low-income and middle-income countries, ${ }^{4}$ SSIs remain the most common healthcare-associated infections in the USA, and the second most frequent in Europe. ${ }^{56}$ The efficacy of surgical antibiotic prophylaxis (SAP) in preventing SSIs is well established. Timely administration of appropriate SAP is considered one of the most effective SSI prevention strategies ${ }^{5}$ as recommended in the WHO global guidelines for prevention of SSIs. ${ }^{7}$

Successful SAP requires administration of one or more antimicrobial agents at appropriate time-points to achieve effective 
antibiotic concentrations at the surgical site at time of incision and throughout surgery. Pharmacokinetic properties determine administration forms and correct timing and intervals of antibiotic (s). ${ }^{5}$ Actual delivery of antibiotics for surgical prophylaxis is commonly carried out within operating theatre (OT) premises. Provision of optimal SAP may be influenced by a number of factors before, during and after surgery. Lack of clarity concerning responsibility for the choice, dose, timing and duration of antibiotics influences decision-making and proper prescription of SAP. ${ }^{8}$ Unresolved issues of workflow and role perceptions have also been reported as obstacles to properly timed SAP. ${ }^{9}$ As a consequence, SAP may be administered too early, ${ }^{10-12}$ too late or not at all, ${ }^{13-16}$ causing unnecessary patient risks. Guidelines do not recommend prolonged SAP administration for preventing SSI. However, prolongation of SAP for $>24$ hours remains prevalent. ${ }^{1718}$

Within the OT setting, the WHO Safe Surgical Checklist $(\mathrm{SSC})^{19}$ includes evidence-based items for prevention of SSI. Use of the SSC has been reported to reduce mortality and complications, including postoperative infections. ${ }^{20}{ }^{21}$ In a previous study investigating changes in perioperative care processes following WHO SSC implementation, we found significant improvements in timely SAP provision preoperatively, within $60 \mathrm{~min}$ before incision. ${ }^{22}$ This was further associated with reduced risk of infections and wound ruptures postoperatively. We aimed to understand possible mechanisms and interactions contributing to these effects, in order to further improve SAP provision. The aim of this study was therefore to outline work flow of SAP provision, including SSC performance of SAP items at the intersection of preoperative procedures and actual team working. The following research questions were addressed: (1) How can SAP work processes be described? (2) What are the key elements in these work processes that influence provision of SAP?

\section{METHODS}

\section{Design}

An ethnographic design was used, where multiprofessional perioperative teams were observed in action in OTs, followed by face-to-face interviews of key informants. This design is well suited to capture 'everyday' routine behaviours in their natural settings. ${ }^{23} 24$

\section{Study setting}

The study was conducted in three hospitals in one Regional Health Authority in Norway; surgical activity and hospital characteristics are described in table 1.

The hospitals operate within separate organisational structures, and perioperative routines vary accordingly. However, SAP use should be compliant with the implemented Norwegian national guidelines of antibiotic use in hospitals. ${ }^{25}$ Furthermore, the WHO SSC had been implemented formally at all sites at the time of the study.

\section{Data collection}

Data triangulation was used in collection of data across time, hospital settings and professions to capture a more complete and contextualised portrait of the studied settings and to validate conclusion of findings. ${ }^{26} 27$ Data collections were limited by available time frames for both the observation and interview time, although saturation of data was met in relation to responsibility of prescription, preparation and administration of SAP.

\section{Perioperative observations}

Data were collected through 40 hours of non-participant observations of perioperative teams in OTs, and through individual interviews of members of these teams (surgeons, OT nurses, anaesthesiologists and nurse anaesthetists). Observations aimed to map routine behaviours on: (1) antibiotic management and (2) team reviews of antibiotic items in the WHO SSC. All team observations took place within local OTs, and followed the entire perioperative phase from the patient arrival in the OT to postoperative delivery. Data were collected from one

\begin{tabular}{|c|c|c|c|c|c|c|}
\hline $\begin{array}{l}\text { Hospitals } \\
(\mathrm{n}=3)\end{array}$ & $\begin{array}{l}\text { Hospital } \\
\text { size }^{\star}\end{array}$ & $\begin{array}{l}\text { Surgical } \\
\text { activity† }\end{array}$ & $\begin{array}{l}\text { Teaching } \\
\text { status }\end{array}$ & $\begin{array}{l}\text { Hospital } \\
\text { level }\end{array}$ & $\begin{array}{l}\text { Medical } \\
\text { service }\end{array}$ & $\begin{array}{l}\text { Organisational } \\
\text { structure }\end{array}$ \\
\hline 1 & 1066 & 33584 & University hospital & $\begin{array}{l}\text { Tertiary referral } \\
\text { hospital }\end{array}$ & $\begin{array}{l}\text { National and Regional } \\
\text { referral hospital for medical } \\
\text { and surgical care }\end{array}$ & $\begin{array}{l}22 \text { specialised } \\
\text { units }\end{array}$ \\
\hline 2 & 149 & 4769 & $\begin{array}{l}\text { Residency training } \\
\text { approval }\end{array}$ & $\begin{array}{l}\text { Secondary care } \\
\text { hospital }\end{array}$ & $\begin{array}{l}\text { General medical and } \\
\text { surgical care }\end{array}$ & 3 specialised units \\
\hline 3 & 244 & 7887 & $\begin{array}{l}\text { Residency training } \\
\text { approval }\end{array}$ & $\begin{array}{l}\text { Secondary referral } \\
\text { hospital }\end{array}$ & $\begin{array}{l}\text { General medical and } \\
\text { surgical care }\end{array}$ & 2 specialised units \\
\hline
\end{tabular}

The Regional Health Authorities have overall responsibility for the specialist health service. Hospital \#1 and \#3 are organised in two separate health trusts, while hospital \#2 is a private, non-profit hospital on contract with the Regional Health Authority. *2016 Occupancy rate (Statistics Norway)=bed days/available bed days. †2016 Reported surgical hospital stays with one or more surgical procedure, based on the classification system of the Norwegian diagnosisrelated groups (N-DRG, Norwegian Patient Registry). 
hospital at a time, with team observations taking place prior to interviews. The observations covered scheduled surgical procedures at dates agreed upon beforehand with the service managers and teams. Three different surgical specialties/subspecialties were included in order to cover different SAP regimes. Observations of team interactions and communications were noted and reviewed by the research team. These field notes were used to develop the interview guide.

Mapping work processes of how antibiotics were managed in a variety of surgical contexts was essential. By 'work processes' we included both the formal documentation for standard procedures of antibiotic prophylaxis as well as the organisational roles and responsibilities, together with informal roles and lines of communication. All observations and interviews were performed by HVW (nurse anaesthetist, trained in qualitative research). ASH (senior nurse anaesthetist, trained in qualitative research) also participated in some of the initial observations (6 hours). Observation notes were compared and discussed between the two observers to validate findings.

\section{Interviews with members of the perioperative team}

Nineteen interviews were performed lasting from 27 to $48 \mathrm{~min}$ in duration, with a median length of $33 \mathrm{~min}$. The interview guide covered three topics: (1) antibiotic management, (2) use of the WHO SSC (with specific focus on SAP items) and (3) teamwork experience (interview guide in online supplementary file 1 ). All healthcare personnel in the perioperative teams were considered key informants. Hence, a maximum variation purposive sampling strategy was used to elicit all perspectives in the provision of SAP in the OTs. ${ }^{28}$ Invitations to participate were initially reviewed and approved by the Directors of the Departments of Research and Development at the respective study hospitals. Participants were recruited by the local managers. Professionals with variable length of perioperative work experience were targeted for sampling; their characteristics are described in table 2.

The interviews were conducted between November 2015 and November 2016, and were conducted in the OT departments, in areas free from distractions (eg, meeting rooms). Each participant was interviewed once. The interviews were audiotaped, transcribed verbatim and transferred to NVivo Pro V.11.4 computer software (QSR International ABN 47006357213) for coding.

\section{Analysis}

Data from observations and interviews were analysed using a content analysis approach, combining deductive and inductive analysis elements. First, to identify the perioperative work process of SAP, a deductive approach was applied using directed content analysis as described by Hsieh and Shannon. ${ }^{28}$ The Norwegian national regulation framework for medication management was applied as coding frame. This regulation framework requires healthcare personnel to adhere to defined responsibilities in the three domains of medication prescription, preparation and administration to ensure that the right medication and dose is administered correctly to the right patient at the right time. ${ }^{29}$ The deductive analysis investigated specific SAP work processes in relation to these three domains of the medication regulation framework, which is also a compulsory part of the curriculum and training for nurses and physicians in Norway. HVW, ASH, ES (consultant anaesthesiologist) and SH (consultant in infectious diseases) participated in the preliminary analysis using group consensus to strengthen coherence of the findings. ${ }^{30}$ Second, to further explore the underlying work processes, an inductive approach was applied with a thematic analysis according to Graneheim and Lundman. ${ }^{31}$ This qualitative content analysis comprises descriptions of the manifest content close to the text as well as interpretations of the latent content

Table 2 Characteristics of informants in the study of surgical antibiotic prophylaxis work processes in Norway, 2015-2016

\begin{tabular}{|c|c|c|c|c|c|c|}
\hline \multirow[b]{2}{*}{ Participant profession } & \multirow[b]{2}{*}{$\begin{array}{l}\text { Number } \\
n=19\end{array}$} & \multirow[b]{2}{*}{$\begin{array}{l}\text { Work-experience } \\
\text { years qualified in } \\
\text { profession-range }\end{array}$} & \multirow[b]{2}{*}{$\begin{array}{l}\text { Sex female/ } \\
\text { male }\end{array}$} & \multicolumn{3}{|c|}{ Participant work place } \\
\hline & & & & $\begin{array}{l}\text { Secondary } \\
\text { care } \\
\text { hospital }\end{array}$ & $\begin{array}{l}\text { Secondary } \\
\text { referral } \\
\text { hospital }\end{array}$ & $\begin{array}{l}\text { Tertiary } \\
\text { referral } \\
\text { hospital }\end{array}$ \\
\hline Nurses* & 12 & $5-30$ & $11 / 1$ & 4 & 4 & 4 \\
\hline \multicolumn{7}{|c|}{$\begin{array}{l}\text { Nurse anaesthetist/operating } \\
\text { theatre nurse }\end{array}$} \\
\hline Physicians $\dagger$ & 7 & $3-30$ & $0 / 7$ & 0 & 4 & 3 \\
\hline \multicolumn{7}{|c|}{$\begin{array}{l}\text { Consultant anaesthesiologist/ } \\
\text { consultant surgeon/surgeon }\end{array}$} \\
\hline Total & 19 & $3-30$ & $11 / 8$ & 4 & 8 & 7 \\
\hline
\end{tabular}

${ }^{*}$ Authorisation requirements in Norway: 3-year bachelor degree in Nursing-180 ECTS*+either a 1.5-year Specialist education program-90 ETCS, or a 2-year Master's program-120 ECTS at a College University degree.

†Authorisation requirements in Norway: 6-year cand. med. degree, 360 ECTS* 6.5 years of specialist training before qualification as consultant.

ECTS, European Credit Transfer and Accumulation System credits. 
distant from the text, yet still close to the participants' experiences. ${ }^{30}$ Statements, observations and interpretations that reflected participants' conditional actions and interactions were identified. The following steps were used: HVW, ASH and SH read the transcribed interviews forming units of analysis. HVW identified and coded transcript sections into 'meaning units', followed by relating categories and theme, constituting the manifest content. ${ }^{31}$

Observational data were used to support the interview data analysis, contributing to the formation and interpretation of emerging themes. ASH and $\mathrm{SH}$ reviewed the coding and interpretations. Preliminary themes, subthemes and quotes were then discussed among the authors (HVW, ASH, ES, SH). In addition, KA and SW (safety scientists, trained in qualitative methods) also participated in finalising analysis of the latent content, the underlying meaning of the text and concluding themes. The finalised dataset is reported in categories and subthemes constituting the overarching descriptive theme, with verbatim quotes from the interviews, and summarised field notes from the observations to support and illustrate each category.

\section{Patient and public involvement statement}

There were no direct patient or public involvement in this study, although the object of study and its relevance to patients have been discussed on several occasions with Head of Patient Involvement Committee in the Western Norway Regional Health Authority. Both observers had previously worked in OTs. The local managers informed all OT staff prior to case observations, and cases where any staff member or the patient withheld consent were excluded.

\section{RESULTS}

Analysis of observations and interviews identified provision of SAP as a process of linked activities, sequenced yet disconnected in time and space during the perioperative phase. The process involved interactions of the multidisciplinary team members before, under and after surgery. The deductive analysis identified the 'who', 'where' and 'when' in relation to initial and follow-up prescription, preparation and administration of SAP. These three domains, as described in the Norwegian regulation framework, constituted the formal steps of the work process. Participants described these steps in relation to the entire perioperative phase, although timing administration of SAP prior to incision was a target.

The inductive analysis identified several challenges of competing demands and varying conditions, in the process of timing administration of SAP within the given timeframe of $60 \mathrm{~min}$ prior to incision. The overarching theme describes provision of SAP as 'a complex process of balancing timeliness while considering and responding to multiple, interacting factors'. The balancing of timeliness and interacting factors were further characterised by three subthemes interpreted from nine categories, which were derived from codes of the deductive and inductive analysis, presented in table 3 . In the following section, the three subthemes and corresponding categories are presented in detail with representative illustrating verbatim quotes.

\section{Handling surgical antibiotic prophylaxis when considering multiple interacting factors}

The formal work processes included participants' perception of roles, responsibility, location and timing of performance related to prescription, preparation and administration of SAP. Prescription of SAP (drug of choice, dosage and duration) was as a rule ordered by the surgeon before the surgical procedure, although verbal prescriptions might also occur during surgery. The surgeon then had to confirm the SAP prescription by signing the anaesthesia and/or postoperative record. This prescribing responsibility was acknowledged by all members of the team. However, diverse prescription order systems with different prescription practices were observed. Some units used electronic surgical planning systems with embedded preoperative standardised SAP prescriptions with default settings.

Nurse anaesthetist: SAP is to be prescribed in the patient's medication chart by the surgeon, if there is an indication. Sometimes, SAP is prescribed in the electronic surgical planning system as well.

Surgeon: As long as the patient belongs to this department SAP is to be prescribed in the medication chart. In case it is not written in the medication chart, then it [the antibiotic] is not prescribed properly.

Other units had written pre-authorised standardised SAP protocols for certain types of surgery, and patientbound signed preoperative medical paper forms of SAP prescription for others. The different preoperative SAP prescription systems varied not only between sites, but also between surgical wards at one of the study hospitals. Nurse anaesthetists also described variations in prescription accuracy, particularly in cases with unclear prescriptions or lack thereof. Sometimes the anaesthesiologist might also be involved in prescription orders such as in endocarditis prophylaxis or when the anaesthesiologist was personally responsible for an interventional procedure, for example, subcutaneous venous port implantations.

Anaesthesiologist: Formally, the surgeon is in charge of the SAP prescription orders, no doubt of that! Within the premises of the operating theatres, I only prescribe SAP to patients if I'm in charge of the procedure, that is, subcutaneous venous port implantations.

Preparations of all SAP infusion(s) or injection(s) were done by nurses. The medication infusions were mainly prepared in the OTs by nurse anaesthetists, but for surgery involving combinations of two antibiotics, infusions were prepared in the surgical ward. 


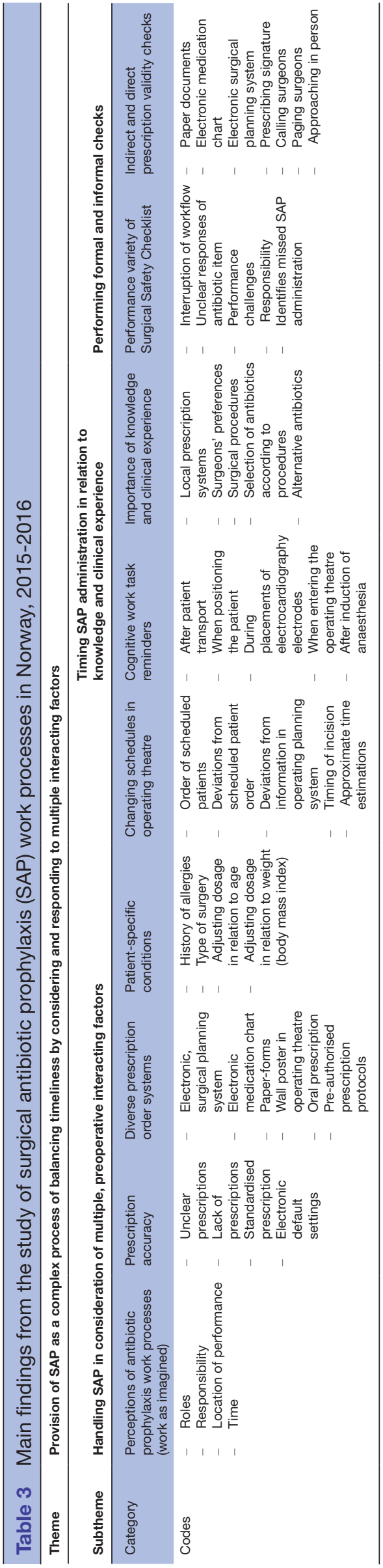

Nurse anaesthetist: For orthopaedic surgery, and for some of the abdominal, like the inguinal hernia repairs, we prepare the SAP ourselves, although sometimes it gets a bit messy, due to suboptimal localities... For some of the other abdominal surgeries.... i.e. cancer surgery, the $\mathrm{SAP}$ is prepared as $500 \mathrm{~mL}$ or $1000 \mathrm{~mL}$ infusions, and both preparations are made at the ward, and brought to the OT along with the patients.

Administration was then started in the surgical ward or the operating holding area: the ward nurse handed over the double controlled and signed infusion containers to the nurse anaesthetist if the infusions were not completed before patient handover. SAPs with short half-lives were both prepared and administered to patients by nurse anaesthetists within the OT. Dosages and time points were documented in the patients' anaesthetic records, registered at a precise time point (injections) or an explicit 'start' and 'stop' time (infusions).

Operating theatre nurse: The anaesthesia team is responsible for SAP administration. Medications, anaesthesia,... this is their responsibility.

Considering patient-specific factors was also described as important when handling SAP. When in need of alternative antibiotic(s) due to patient allergies, adjustments in timely administration of SAP had to be reconsidered, according to the pharmacokinetic property of the alternative antibiotics, especially half-lives. This was not always clarified prior to the patient's arrival in the OT. Clarifications on the precise SAP dosages in cases of elder, paediatric, and/or adipose patients were also reported by informants as important, yet time-consuming considerations in the planning or preparation of SAP.

The type of surgery initially determined the SAP regimes. Hence, the OT scheduling of patients also influenced SAP work processes. The scheduled order of the different surgical procedures in the OT with corresponding specific SAP regimes generated fluctuating SAP work processes throughout the day. With the exception of the first patient admitted to the OT, the timings of incision for the remaining scheduled patients were based on approximate time estimations with SAP being administered according to these estimations.

Nurse anaesthetist: It is much easier to provide right timing of SAP to the first scheduled patient of the day, because we have an exact point of time scheduled for this patient. Throughout the day, it gets more complicated, because it is difficult to predict the time of arrival and administration of SAP, for the next patients.

Participants described cases where information in the operating planning system, including SAP prescriptions, deviated from agreed (or perceived as agreed) on perioperative standards. Furthermore, abrupt changes in preoperative scheduling, lack of signed preoperative 
prescriptions and uncertain SAP indications also caused variations in the preparations and administration of SAP.

Timing administration of surgical antibiotic prophylaxis using clinical knowledge and experience

The participants described how specific preoperative work tasks served as cognitive reminders for SAP administration within the preferred timeframe. This was explained as particularly helpful for the anaesthesia team as both preparation and administration of SAP might easily be influenced by concurrent tasks, distracting them in timely provision of SAP. This was confirmed through observations, especially during induction of anaesthesia. The anaesthesia team explained how linking SAP administration concurrently to other specific work tasks made it easier for them remembering to administer SAP within the recommended timeframe of $60 \mathrm{~min}$. Such work tasks included patient transport, patient positioning or electrocardiography electrodes placement.

Nurse anaesthetist: For orthopaedic patients, they are first transported to anaesthetic room, for application of anaesthesia. Then, there is a timespan where SAP may be administered, before the patient is transported into the OT.

SAP administration was also emphasised to be carried out at specific points of time in the preoperative phase such as when entering the OT, when positioning the patient or after induction of anaesthesia.

Anaesthesiologist: As a routine, I believe that the SAP is administered during induction of anaesthesia, just after we have inserted the central venous catheter.

Use of the WHO SSC, with the item for specified timeframe of SAP provision within $60 \mathrm{~min}$ prior to incision, was also described as a reminder. Most of the nurse participants reported that the WHO SSC implementation had made them more aware of this timeframe. Knowledge and experience on surgical routines and workflow in the OTs, in addition to the local SAP regimes, were also highlighted as important among the participants. This was described as being experience gained on the standardised surgical procedures and the types of antibiotics used as standard prophylaxis for the different procedures performed at their surgical unit. In addition, participants emphasised the need to have knowledge on alternative SAPs used in cases of identified antibiotic allergies.

Nurse anaesthetist: When you have some experience, you know which type of surgeries that requires SAP, and which types of surgeries that do not, because you recognise the indications, even though prescriptions are not clear.

\section{Performing formal and informal checks}

Both formal and informal SAP checks were carried out in the preoperative phase as illustrated in figure 1, which outline the workflow for SAP including different checkpoints. The Safe Surgical Checklist constituted the formal, compulsory check. Prior to incision, the perioperative teams paused and performed a 'time-out' according to the WHO SSC with items questioning whether SAP had been provided read aloud. Varying team-briefing responses as to these SSC SAP items were observed. Some team responses concentrated on the timing of SAP administration, some reviewed if prescribed dosages correlated to the actual administered SAP and some left responses to the SSC items out completely. During performance of the formal SSC, and specifically when addressing SAP items during the SSC team briefings, some of the OT nurses were reluctant, because they felt like questioning aloud whether the anaesthesia team had performed their job or not. If the anaesthesia team failed to respond, repetition of these SSCs items was then ignored.

Operating theatre nurse: My only worry-personally-is to ask the anaesthesia team whether they have done their job or not. I really struggle with this checklist item (SAP). I get this awkward feeling ... It's like poaching on somebody's preserve.

The informants also described episodes where surgeons did not wait (but carried on with incision) despite the 'time-out' briefings having identified missing or delayed SAP administration. This was also confirmed by observations.

Surgeon: No, I don't think that I have ever experienced to stop and await incision, in cases where SAP has not been fully administered.

The physicians' responses were explained by an overall concern of delay causing surgical programme flow disruptions and prolonging time of anaesthesia. However, in cases where surgery required application of a tourniquet, surgeons delayed incision in order to let the SAP work appropriately.

Operating theatre nurse: No, the surgeons do not await incision if SAP is missing. Only if the tourniquet is already applied, then they have to wait.

Informal SAP checks were performed by the anaesthesia teams to clarify which antibiotic to administer, the dosages and duration. For the SAP to be administered by the nurse anaesthetists in the OT, SAP prescription orders should have been documented and signed preoperatively according to local prescription systems involved, that is, written paper orders, electronic orders or orders in the patient medical chart. The informants emphasised that SAP prescriptions also had to be checked to ensure validity of the prescription order, as default settings in the electronic surgical planning system might cause an unintentional or incorrect SAP prescription.

Nurse anaesthetist: Well, if SAP is not prescribed initially, and the surgeon arrives in theatre and announces that we need to administer antibiotic prophylaxis....Then, I need to make the surgeon sign 


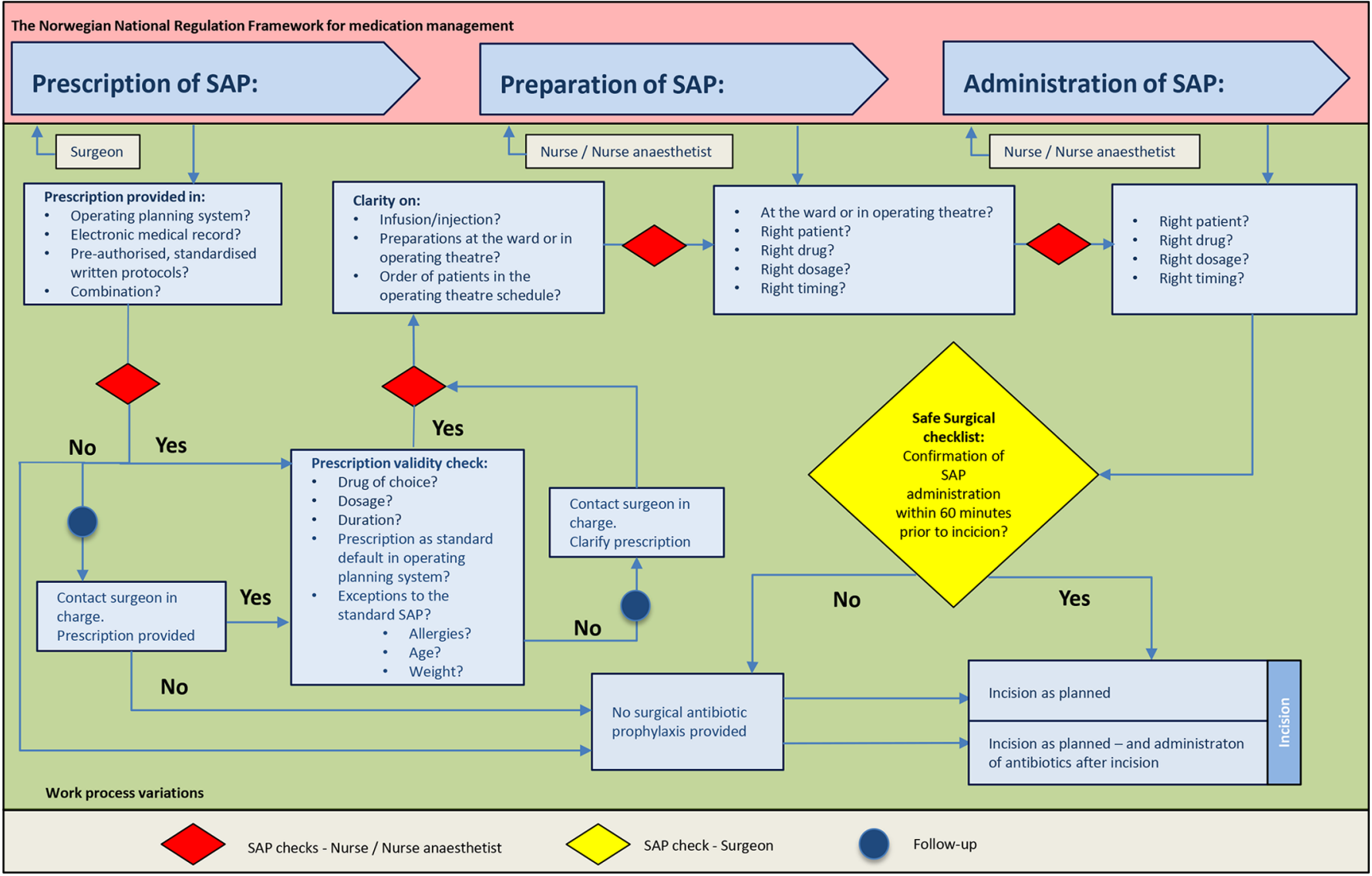

Figure 1 The clinical pathway of surgical antibiotic prophylaxis (SAP): an outline of the workflow for SAP in perioperative care.

the patient's medical record. I present the medical record to the surgeon and then...sign here, please!

The surgeons in charge were contacted in cases of partial or missing SAP prescription orders, or if anyone in the anaesthesia team was in doubt of whether or not to administer the SAP. Surgeons were contacted by phone or pager or by approaching them when they entered the OT. These actions were taken by members of the anaesthesia team themselves or by the OT nurses on behalf of the former.

Anaesthesiologist: Normally, the nurse anaesthetist calls the surgeon if SAP prescriptions are missing.

\section{DISCUSSION}

This study has identified provision of SAP as a complex process of balancing timeliness by considering and responding to multiple interacting factors. Our findings of the multiple considerations and compensating mechanisms used particularly in the preoperative phase, highlight the real-world balancing of professional judgements regarding patient, antibiotic and surgery-related factors as well as coordinating the OT scheduling and workflow for SAP to be administered in due time before incision. Even though perceptions of responsibility in relation to SAP prescription, preparation and administration were consistent among team members, our results indicate ambiguities in ownership for SAP. This was seen especially at intersections of prescription transfers to providers, where suboptimal use of the prescription order systems or poorly completed SAP orders may provide unclear indications for SAP to its actual providers. In addition, the team performances on the WHO SSC including reviews of antibiotic items varied during the 'time-out' part of the SSC, also with a reluctance to address SAP items, described by the OT nurses. The nurse anaesthetist, surgeon and anaesthetist each seem to have self-perceived defined roles in provision of SAP, and yet these roles did not seem to be aligned or sufficiently understood through shared decision-making. Consequently, possible risks of SAP failures were poorly understood or defined at each step in the preoperative planning of surgery.

Existing surgical workflow systems have previously been identified by surgeons and anaesthesiologists as an obstacle to proper timing of SAP, also with work processes of SAP being of low priority among their many perioperative responsibilities. ${ }^{9}$ Yet, studies investigating predictors for appropriate antibiotic use found that patients were more likely to receive an effective and timely first SAP dose when preoperative orders were written and implemented in the OTs. ${ }^{32} 33$ We identified a number of interacting considerations that might help to understand factors and situations influencing timely provision of SAP. One contributor to delayed SAP administration was ignored identification of patients' allergies, or the lack of such being properly addressed. This 
has also been reported by others, with administration of an effective first prophylactic dose being less likely when a patient had a beta-lactam allergy, increasing the risk of SSI. ${ }^{33}$ Another identified contributor to delayed SAP administration was the need to clarify the precise SAP dosages in cases of elder, adipose or paediatric, especially neonate, patients. As these subgroups of surgical patients (age $<60$ weeks and $>75$ years, obesity with body mass index $(\mathrm{BMI})>30$, morbid obesity with $\mathrm{BMI} \geq 40$ ) are reported to have an increased risk of developing SSIs based on their physical status, delayed SAP administrations adds to these risks. ${ }^{25}{ }^{34}$ The classification of patients' physical status (America Society of Anesthesiologists classification) has previously been identified as a significant predictor of SSIs. ${ }^{35}$ Patients with an impaired physical status should therefore be given extra attention during the planning and prescription of SAP. Although our findings describe the surgeons as being responsible for SAP prescriptions, the anaesthesiologists have responsibility for patient assessments as to potential allergies and physical status. This imbalance of responsibilities might contribute to unclear SAP prescription orders with risks of delayed SAP administrations. ${ }^{36}$ Furthermore, our findings indicate that suboptimal use of the prescription order systems or poorly completed SAP orders may provide unclear indications for SAP to its actual providers. Especially the nurse anaesthetist performed additional informal SAP checks, and the surgeons were contacted when in doubt of SAP indication or the validity of the prescription order. Nevertheless, the need to spend crucial minutes in the OTs to clarify prescription orders as illustrated in figure 1, inadvertently leaves a narrower timeframe for the nurse anaesthetist to administer SAP on time ( $60 \mathrm{~min}$ prior to incision). A narrower timeframe in itself, in turn, increases risk of SAP administration delays. A comparison on the risk of SSI with different timing intervals of SAP was addressed in a recent meta-analysis. ${ }^{37}$ The analysis showed that the risk of SSIs almost doubled when SAP was administered after incision compared with before incision, and resulted in 25 more infections per 1000 treated patients. ${ }^{37}$

This study builds on previous research which reported significant improvements in timely SAP provision preoperatively before incision following implementation of the WHO SSC. ${ }^{22}$ The key novelty of our findings show how implementation of the SSC may facilitate resilient mechanisms within the team, in relation to specific work processes of SAP. This is supported by how timing administration of antibiotics was performed. We found that this was executed mainly by nurse anaesthetists, in relation to their knowledge and clinical experience of workflow in surgery, and the performance of prescription checks at different time points before incision (figure 1). A key element that seems to drive tasks and behaviours related to SAP administration was the given timeframe of $60 \mathrm{~min}$ prior to incision as provided in the SSC. This suggests that the SSC might serve as a cognitive tool to drive SAP administration to take place prior to incision. In addition, by being aware of the timeframe the providers of SAP were able to respond to regular and irregular variabilities in prescriptions by questioning uncertainties and adjusting timing of SAP administration according to disturbances in the OT workflow.

However, the identified various team responses during the 'time-out' part of the SSC as well as a reluctance to address SAP items, indicates a lack of SSC quality performance at full length. In a previous study, we have identified how nurses used a variety of strategies to adjust team involvement when encountering resistance to the SSC from members of the surgical team. ${ }^{38}$ This included avoiding completing the checklist entirely, or selectively completing some items with specific team members. Both strategies resulted in decreased quality of the SSC process. This shows that obstacles stemming from the SSC apply to the content and to psychological ownership. ${ }^{39}$ Moderate compliance rates of SSC utilisation as well as poor performance quality have also been identified in previous studies. ${ }^{40-42}$ Furthermore, we found that identification of missing or delayed SAP prescription or administration during SSC Time-Out reviews, seldom resulted in delays of incision, although this is recommended in guidelines. $^{43}$

Our findings indicate that the SSC is likely to identify missed SAP administrations, yet does not prevent surgical incision to take place before SAP administration. However, having established focus on the timeframe of completing SAP administration within $60 \mathrm{~min}$ prior to incision through SSC use might have influenced SAP administration practise indirectly. The nurse anaesthetist more likely responds in a prompt manner to unclear prescriptions, and adjusts timing of administration in accordance with the SSC recommendations. To strengthen SSC use as a safety barrier to minimise risk of SSI, we suggest that SAP prescription checks should also be done by the nurse anaesthetist at the SSC Sign-In in addition to the surgeons' already established controls of SAP administration at Time-Out (figure 1). This should also reduce risk of interfering with the time point for incision and possible delays in OT schedules. Such clarifications via preoperative team briefings have previously been associated with improved clinical practice of timely SAP administration. ${ }^{44}$

\section{Recommendations and further research}

Antibiotic stewardship programmes are of particular importance to surgical specialties due to their prominent role in prophylactic antibiotic usage and management of surgical infections, and may serve as suitable frameworks to address correct provision of SAP. ${ }^{45}$ Multidisciplinary team roles and pathways specifying timing and sequence of responsibilities are recommended to influence teamlevel communications and workflow. ${ }^{46}$ Based on our findings we advocate that objectives and measures of antibiotic stewardship programmes in surgery must include both nurse providers of SAP as well as the surgeon prescribers. Our findings illustrate how nurses, particularly nurse anaesthetists, are important stakeholders in SAP provision when responding to unclear prescriptions and adjusting time of SAP administration according to 
the timeframe provided in the SSC. Nurses' role in antibiotic stewardship practices in hospitals have previously been emphasised. ${ }^{47}$ To our knowledge, their role and responsibility of SAP in the perioperative period has not been described before.

Further research should investigate how the roles and responsibilities of nurses and nurse anaesthetists regarding SAP management for surgical patients could be expanded. In addition, antibiotic stewardship programmes in surgery should test SAP delivery interventions, and measure performance indicators of timely SAP administrations as well as prescription adherence to guidelines. We suggest that education of SAP indications and the pharmacokinetic properties of the antibiotic used as prophylaxis may further support SAP providers to target SAP timing according to the half-life of the prescribed antibiotic. Also, providing feedback on timeliness of SAP administration as performance indicator will allow nurses and nurse anaesthetists to take ownership in improving provision of timely SAP. ${ }^{46}$

\section{Study limitations}

This study was conducted in surgical settings in Norway. Recommendations of SAP regimes were based on the Norwegian national guidelines of antibiotic use in hospitals. The identified work processes and mechanisms might therefore be limited to reflect practice in Norway. However, international recommendations indicate that SAP should be initiated within $60-120 \mathrm{~min}$ prior to surgical incision, based on its pharmacokinetic property. ${ }^{5}$

In order to achieve credible information on the SAP work processes, data triangulation was used by collecting data across time, hospital settings and professions. ${ }^{26}$ Also, combinations of individual interviews and observations of team interactions in the OTs, made it possible to collect data showing actual behaviours in their natural settings. ${ }^{23}{ }^{24}$ Although all members of the multidisciplinary surgical team were represented, interview selection bias was a possibility. Despite our maximum variation purposive sampling strategy, ${ }^{28}$ a majority of the informants turned out to be experienced clinicians (table 2), which likely reflected and limited the range of responses compared with if junior team members had been involved. By use of the ethnographic approach, possible risks of SAP failures and possible explanations of their occurrence have been identified. Larger follow-up studies on procedures, work practices and measures of SAP provision are required to achieve more generalisable findings.

\section{CONCLUSION}

This study has explored SAP work processes in the preoperative period and outlined how the multitude of considerations in handling SAP may influence, and delay its administration. Yet, a key element to proper SAP that supports timely provision is the given timeframe of administration, focused on by SSC use. Thus, the introduction of SSC, emphasising SAP administration $60 \mathrm{~min}$ prior to incision, is likely to have influenced administration practice through the following mechanisms: (1) as a cognitive tool, in helping the nurse anaesthetist to remember timing of SAP administration, (2) as an educational intervention, facilitating resilience by making SAP providers able to respond promptly when in need of clarifications of prescriptions, to ensure SAP administration before incision.

\section{Author affiliations}

${ }^{1}$ Department of Research and Development, Haukeland University Hospital, Bergen, Norway

${ }^{2}$ Department of Clinical Science, Faculty of Medicine, University of Bergen, Bergen, Norway

${ }^{3}$ Department of Anaesthesia and Intensive Care, Haukeland University Hospital, Bergen, Norway

${ }^{4}$ Department of Clinical Medicine, Faculty of Medicine, University of Bergen, Bergen, Norway

${ }^{5}$ Centre for Implementation Science, Health Service \& Population Research

Department, King's College, London, UK

${ }^{6}$ Department of Essential Medicines and Health Products, World Health Organization, Geneve, Switzerland

${ }^{7}$ Centre for Resilience in Healthcare (SHARE), Faculty of Health Sciences, University of Stavanger, Stavanger, Norway

Acknowledgements The authors would like to thank the perioperative team members who contributed to this study by sincerely sharing their experiences and thoughts of teamwork and related work processes in relation to surgical antibiotic prophylaxis. The authors would like to thank the local managers within the different surgical departments for their helpful facilitation of the observations and for providing informants for the interviews. The authors would also like to thank Håkon Ersland, Department of Research and Development, Haukeland University Hospital for help in providing data in Table 1 and Table 2, and Trond Wæhle, Helse Vest IKT, for help in designing Figure 1. The study was endorsed by the National Advisory Unit for Antibiotic Use in Hospitals in Norway.

Contributors HVW, IS, ES, SH and ASH conceived of and designed the study. HVW carried out the data collection, ASH participated in some of the observations. HVW, ASH, SH, ES performed preliminary analysis, KA and SW participated in finalising the analysis, and provided input in relation to methodology matter. All authors (HVW SH, ES, NS, IS, SW, KA and ASH) participated in interpretation of the study results, assisted in manuscript revision and approved the final draft.

Funding This work was supported by grants from the Western Norwegian Regional Health Authority with grant numbers, respectively: HV1174 (HVW) and HV1172 (AH). The research by NS is funded by the NIHR via the 'Collaboration for Leadership in Applied Health Research and Care South London' at King's College Hospital NHS Foundation Trust, London, UK. NS is also a member of King's Improvement Science, which is part of the NIHR CLAHRC South London and comprises a specialist team of improvement scientists and senior researchers based at King's College London. Its work is funded by King's Health Partners (Guy's and St Thomas' NHS Foundation Trust, King's College Hospital NHS Foundation Trust, King's College London and South London and Maudsley NHS Foundation Trust), Guy's and St Thomas' Charity, the Maudsley Charity and the Health Foundation. NS is also supported by the NIHR Global Health Research Unit on Health System Strengthening in sub-Saharan Africa, King's College London (GHRU 16/136/54) and by the ASPIRES research programme in LMICs (Antibiotic use across Surgical Pathways-Investigating, Redesigning and Evaluating Systems), funded by the Economic and Social Research Council of the UK.

Disclaimer The views expressed are those of the authors and not necessarily those of the NHS, the NIHR or the Department of Health. The funders had no role in the design, conduct or analysis of this study.

Competing interests NS is the Director of London Safety and Training Solutions Ltd, which provides quality and safety training and advisory services on a consultancy basis to healthcare organisation globally.

Patient consent for publication Not required.

Ethics approval The study was reviewed by the Regional Ethics Committee, REK Vest, of the Western Norway Health Region (2015/1741) prior to data collection, who recommended that the study be reviewed by hospital management and data privacy ombudsman for research (DPO). The DPO reviewed and approved the study prior to data collection. All study participants gave their informed, written consent 
to participate prior to the interviews, and could withdraw from the study at any time.

Provenance and peer review Not commissioned; externally peer reviewed.

Data sharing statement The datasets analysed during the current study are not publicly available due to confidentiality issues, but can be made available (in Norwegian) from the corresponding author on reasonable request.

Open access This is an open access article distributed in accordance with the Creative Commons Attribution Non Commercial (CC BY-NC 4.0) license, which permits others to distribute, remix, adapt, build upon this work non-commercially, and license their derivative works on different terms, provided the original work is properly cited, appropriate credit is given, any changes made indicated, and the use is non-commercial. See: http://creativecommons.org/licenses/by-nc/4.0/.

\section{REFERENCES}

1. Boyce JM, Potter-Bynoe G, Dziobek L. Hospital reimbursement patterns among patients with surgical wound infections following open heart surgery. Infect Control Hosp Epidemiol 1990;11(2):89-93.

2. Poulsen KB, Bremmelgaard A, Sørensen Al, et al. Estimated costs of postoperative wound infections. A case-control study of marginal hospital and social security costs. Epidemiol Infect 1994;113(2):283-95.

3. Vegas AA, Jodra VM, García ML. Nosocomial infection in surgery wards: a controlled study of increased duration of hospital stays and direct cost of hospitalization. Eur J Epidemiol 1993;9(5):504-10.

4. Allegranzi B, Bagheri Nejad S, Combescure C, et al. Burden of endemic health-care-associated infection in developing countries: systematic review and meta-analysis. Lancet 2011;377(9761):228-41.

5. Anderson DJ, Sexton DJ. Antimicrobial prophylaxis for prevention of surgical site infection in adults: UpToDate; 2018 [updated Mar 09, 2018]. Available: https://www.uptodate.com/contents/antimicrobialprophylaxis-for-prevention-of-surgical-site-infection-in-adults2018

6. European Centre for Disease Prevention and Control. Surgical site infections - Annual Epidemiological Report 2016 European Centre for Disease Prevention and Control. 2016. Available: https://ecdc. europa.eu/en/publications-data/surgical-site-infections-annualepidemiological-report-2016-2014-data

7. Allegranzi B, Bischoff $\mathrm{P}$, de Jonge $\mathrm{S}$, et al. New WHO recommendations on preoperative measures for surgical site infection prevention: an evidence-based global perspective. Lancet Infect Dis 2016;16(12):e276-e287.

8. Charani E, Tarrant C, Moorthy K, et al. Understanding antibiotic decision making in surgery-a qualitative analysis. Clin Microbiol Infect 2017;23(10):752-60.

9. Tan JA, Naik VN, Lingard L. Exploring obstacles to proper timing of prophylactic antibiotics for surgical site infections. Qual Saf Health Care 2006;15(1):32-8.

10. Galandiuk S, Polk HC, Jagelman DG, et al. Re-emphasis of priorities in surgical antibiotic prophylaxis. Surg Gynecol Obstet 1989;169(3):219-22.

11. Lizán-García M, García-Caballero J, Asensio-Vegas A. Risk factors for surgical-wound infection in general surgery: a prospective study. Infect Control Hosp Epidemiol 1997;18(5):310-5.

12. Silver A, Eichorn A, Kral J, et al. Timeliness and use of antibiotic prophylaxis in selected inpatient surgical procedures. The Antibiotic Prophylaxis Study Group. Am J Surg 1996;171(6):548-52.

13. Bull AL, Russo PL, Friedman ND, et al. Compliance with surgical antibiotic prophylaxis-reporting from a statewide surveillance programme in Victoria, Australia. J Hosp Infect 2006;63(2):140-7.

14. Castella A, Charrier L, Di Legami V, et al. Surgical site infection surveillance: analysis of adherence to recommendations for routine infection control practices. Infect Control Hosp Epidemiol 2006;27(8):835-40.

15. Rosenberg AD, Wambold D, Kraemer L, et al. Ensuring appropriate timing of antimicrobial prophylaxis. J Bone Joint Surg Am 2008;90(2):226-32.

16. Muller A, Leroy J, Hénon T, et al. Surgical antibiotic prophylaxis compliance in a university hospital. Anaesth Crit Care Pain Med 2015;34(5):289-94.

17. Friedman ND, Styles K, Gray AM, et al. Compliance with surgical antibiotic prophylaxis at an Australian teaching hospital. Am J Infect Control 2013;41(1):71-4.

18. Shawyer AC, Hatchell AC, Pemberton J, et al. Compliance with published recommendations for postoperative antibiotic management of children with appendicitis: A chart audit. J Pediatr Surg 2015;50(5):783-5.
19. World Health Organization. WHO surgical safety checklist implementation. http://www.who.int/patientsafety/safesurgery/ checklist_implementation/en/

20. Bergs J, Hellings J, Cleemput I, et al. Systematic review and meta-analysis of the effect of the World Health Organization surgical safety checklist on postoperative complications. Br J Surg 2014;101(3):150-8.

21. Haugen AS, Søfteland E, Almeland SK, et al. Effect of the World Health Organization checklist on patient outcomes: a stepped wedge cluster randomized controlled trial. Ann Surg 2015;261(5):821-8.

22. Haugen AS, Wæhle HV, Almeland SK, et al. Causal Analysis of World Health Organization's Surgical Safety Checklist Implementation Quality and Impact on Care Processes and Patient Outcomes: Secondary Analysis From a Large Stepped Wedge Cluster Randomized Controlled Trial in Norway. Ann Surg 2019;269:283-90. doi: 10.1097/SCS.0000000000005565.

23. Dixon-Woods M. What can ethnography do for quality and safety in health care? Qual Saf Health Care 2003;12(5):326-7.

24. Cupit C, Mackintosh N, Armstrong N. Using ethnography to study improving healthcare: reflections on the 'ethnographic' label. BMJ Qual Saf 2018;27(4):258-60.

25. Norwegian Directorate of Health. Nasjonal faglig retningslinje for bruk av antibiotika i sykehus: Norwegian Directorate of Health, 2013.

26. Denise F, Polit CTB. Nursing research: generating and assessing evidence for nursing practice. 8 edn. Philadelphia: Lippincott Williams \& Wilkins, 2008.

27. Cresswell J. Qualitative Inquiry \& Research Design:choosing among five approaches. 3 edn. Thousand Oaks, California: Sage Publications, 2013.

28. Hsieh HF, Shannon SE. Three approaches to qualitative content analysis. Qual Health Res 2005;15(9):1277-88.

29. The Ministry of Health and Care services, the Storting. Forskrift om legemiddelhåndtering for virksomheter og helsepersonell som yter helsehjelp av 2008-04-03 nr. 320. 2008 https://lovdata.no/dokument/ SF/forskrift/2008-04-03-320.

30. Graneheim UH, Lindgren BM, Lundman B. Methodological challenges in qualitative content analysis: A discussion paper. Nurse Educ Today 2017;56:29-34.

31. Graneheim UH, Lundman B. Qualitative content analysis in nursing research: concepts, procedures and measures to achieve trustworthiness. Nurse Educ Today 2004;24(2):105-12.

32. Hawn MT, Gray SH, Vick CC, et al. Timely administration of prophylactic antibiotics for major surgical procedures. J Am Coll Surg 2006;203(6):803-11.

33. Turnbull BR, Zoutman DE, Lam M. Evaluation of hospital and patient factors that influence the effective administration of surgical antimicrobial prophylaxis. Infect Control Hosp Epidemiol 2005;26(5):478-85.

34. Committee AHoDE. ASA Physical Status Classification System: American Society of Anesthesiologists. 2014. Available https:// www.asahq.org/standards-and-guidelines/asa-physical-statusclassification-system2019.

35. Woodfield JC, Beshay NM, Pettigrew RA, et al. American society of anesthesiologists classification of physical status as a predictor of wound infection. ANZ J Surg 2007;77(9):738-41.

36. Broom JK, Broom AF, Kirby ER, et al. How do professional relationships influence surgical antibiotic prophylaxis decision making? A qualitative study. Am J Infect Control 2018;46(3):311-5.

37. de Jonge SW, Gans SL, Atema JJ, et al. Timing of preoperative antibiotic prophylaxis in 54,552 patients and the risk of surgical site infection: A systematic review and meta-analysis. Medicine 2017;96(29):e6903.

38. Wæhle HV, Haugen AS, Søfteland E, et al. Adjusting team involvement: a grounded theory study of challenges in utilizing a surgical safety checklist as experienced by nurses in the operating room. BMC Nurs 2012;11:16.

39. Bergs J, Lambrechts F, Simons P, et al. Barriers and facilitators related to the implementation of surgical safety checklists: a systematic review of the qualitative evidence. BMJ Qual Saf 2015;24(12):776-86.

40. Ambulkar R, Ranganathan P, Salunke K, et al. The World Health Organization Surgical Safety Checklist: an audit of quality of implementation at a tertiary care high volume cancer institution. $J$ Anaesthesiol Clin Pharmacol 2018;34(3):392-8.

41. Cullati S, Le Du S, Raë AC, et al. Is the surgical safety checklist successfully conducted? An observational study of social interactions in the operating rooms of a tertiary hospital. BMJ Qual Saf 2013;22(8):639-46.

42. Rydenfält $\mathrm{C}$, Johansson $\mathrm{G}$, Odenrick $\mathrm{P}$, et al. Compliance with the WHO Surgical Safety Checklist: deviations and possible improvements. Int J Qual Health Care 2013;25(2):182-7. 
43. Wahr JA. Operating room hazards and approaches to improve patient safety. 06.01.2019 ed: UpToDate, $2019 \mathrm{https}: / / \mathrm{www}$. uptodate.com/contents/operating-room-hazards-and-approachesto-improve-patient-safety?sectionName=Checklists\&topicRef $=4044$ \& anchor=H585585358\&source=see_link\#H585585358.

44. Lingard L, Regehr G, Cartmill C, et al. Evaluation of a preoperative team briefing: a new communication routine results in improved clinical practice. BMJ Qual Saf 2011;20(6):475-82.
45. Tarchini G, Liau KH, Solomkin JS. Antimicrobial stewardship in surgery: challenges and opportunities. Clin Infect Dis 2017;64:S112-S114

46. Gagliardi AR, Fenech D, Eskicioglu C, et al. Factors influencing antibiotic prophylaxis for surgical site infection prevention in general surgery: a review of the literature. Can J Surg 2009;52(6):481-9.

47. Gillespie E, Rodrigues A, Wright L, et al. Improving antibiotic stewardship by involving nurses. Am J Infect Control 2013;41(4):365-67. 